\title{
Strategic Management Knowledge Transfer, Absorptive Capacity and the Attainment of Strategic Objective of MNCs' Chinese Subsidiaries"
}

\author{
Ling Hu \\ Dongling School of Economics and Management, University of Science and Technology, Beijing, China \\ Email: huling@ustb.edu.cn
}

Received April 5, 2012; revised April 21, 2012; accepted May 20, 2012

\begin{abstract}
Different types of knowledge such as R\&D, marketing, and manufacturing knowledge have been focused in the past researches, while few scholars paid attention to strategic management knowledge. This paper focuses on the attainment of strategic objective of MNCs' Chinese subsidiaries, by analyzing the strategic management knowledge transfer from MNC headquarters to the Chinese subsidiaries. The influence of organizational culture, trust and absorptive capacity on the attainment of strategic objective was examined. 115 Chinese subsidiaries were surveyed in the empirical research, showing different results under the Chinese market background. This paper offers a new perspective for the further researches of knowledge transfer and the strategic management practices.
\end{abstract}

Keywords: Strategic Management Knowledge; Knowledge Transfer; Absorptive Capacity; Strategic Objective

\section{Introduction}

As knowledge-based resources play an increasingly important role in sustaining high performance of firms (Kogut \& Zander, 1993) [1], strategy management knowledge is becoming more and more crucial for firms to win in the competition, especially for geographically dispersed MNCs. However, the construct of strategic management knowledge is ignored for a long period of time in the knowledge transfer researches. Therefore, to define strategy management knowledge and figure out its transfer mechanism between MNC headquarters (HQ) and Chinese subsidiaries is critical for theory development concerning both knowledge management and international business management.

China is the best database for investigating knowledge transfer between MNC HQ and subsidiary, since there is no other place than China having so many MNC subsidiaries. Concerning the development of Chinese subsidiaries of MNCs, new changes have been taking place. However, in this paper, both International Joint Venture (IJV) and wholly-owned venture will be chosen as research targets.

Based on the literature review, a theoretical model was put forward, related hypotheses were testified in the em-

*Supported by China Postdoctoral Science Foundation (Grant No. 2011M500245) and the Fundamental Research Funds for the Central Universities (Grant No. FRFTP12119A). pirical research, and implications for the future research and management practice were discussed finally.

\section{Theoretical Model and Hypotheses}

\subsection{Strategic Management Knowledge Transfer}

Most of the literatures on knowledge management are based on knowledge theory (Kogut \& Zander, 1993) [1], which holds that knowledge is firms' specific property, difficult to imitate, and untradable (Barney, 1986) [2]. Knowledge is the key resource of enterprise development, and knowledge difference is the root reason of performance difference among firms (e.g. Teece, Pisano and Sheun, 1997) [3].

Concerning research on knowledge transfer, most of the past studies focus on technological knowledge; among the non-technological knowledge studies, most are about general management knowledge, marketing knowledge and manufacturing knowledge, with very few focusing on strategic management knowledge (Simonin, 1999a) [4]. One of the reasons why strategic management knowledge was neglected could be the ambiguity of this construct, since strategic management is a relatively new discipline originating mainly from 1970s (Mahoney \& McGahan, 2007) [5].

The construct of strategic management knowledge should be defined detailedly. Sanchez (1996) [6] suggested using 3 levels of know-how, know-why and know- 
what to define knowledge. While Wong, Maher, Luk (2002) [7] defined it as basic strategic knowledge knowhow, viz. mission, goals, objectives, environmental analysis, strategy formulation, strategy implementation, evaluation and feedback.

To make it more practical in the empirical researches, interview was implemented. 3 Chinese subsidiaries were contacted and arranged interviews, and the top management team (TMT) was interviewed in a time span of around 2 months, involving 7 members totally. Semistructural interview was implemented, and the expected result was basically achieved. Based on the literature review and materials from interviews, the definition of strategic management knowledge was defined as: The long lasting knowledge, such as strategic business values, operational model of core businesses, enterprise culture values, and business routines etc.

The theoretical model was raised accordingly. Organizational distance and trust are independent variables. Absorptive capacity will be the mediator; and the attainment of strategic objective of Chinese subsidairies will be used as dependent variable (see Figure 1). Firm type will be the controlled variable.

\subsection{Organizational Distance}

According to Simonin (1999b) [8], organizational distance "captures the degree of dissimilarity between the partners business practices, institutional heritage, and organizational culture". Baughn, Stevens, Denekamp \& Osborn (1997) [9] maintained that the huge difference of firm size between partners would lead to the difference of authority, causing the weaker side too difficult to keep their technology confidential and stay in the alliance. Mosakowski (1997: 422) [10] also submitted that organizational culture was one important variable of causal ambiguity, and large organizational culture difference would definitely lead to higher level of ambiguity between the two partners.

According to Choi \& Lee (1997) [11], the larger the cultural distance between the partners, the more difficult the inter-organizational knowledge transfer will be. Therefore, organizational distance can raise the barrier of knowledge transfer due to the ambiguity they raise for the firms. Hence,

Hypothesis 1a: The larger the organizational distance between MNC HQ and Chinese subsidiary, the less the attainment of strategic objective of Chinese subsidiary.

\subsection{Trust}

There is a rich literature on the research of trust, including trust between individuals (Butler, 1991) [12], inter-organizational trust (Nooteboom et al., 1997) [13], and trust between individual and organization (Zaheer, McEvily \& Perrone, 1998) [14]. In this paper, trust was referred to the mutual trust between MNC HQs and Chinese subsidiaries, that is, inter-organizational trust.

Actually trust functions like both a social control mechanism and risk reducing mechanism. Uzzi (1996) [15] posited that trust can work as governance mechanism in the embedded relationships, increasing the exchange of tacit knowledge related capability and information. Trust can also influence the extent of knowledge exchange (Inkpen, 1997) [16] and the knowledge exchange efficiency (Kogut, 1988) [17].

In IJV and strategic alliance researches, many scholars emphasized the importance of mutual trust between partners for the success (Inkpen \& Beamish, 1997) [18]. Hence,

Hypothesis 1b: The stronger the trust between MNC HQs and Chinese subsidiaries, the more the attainment of strategic objective of Chinese subsidiary.

\subsection{Absorptive Capacity}

Absorptive capacity was a very important construct in the studies of knowledge management, and was well defined by many scholars, such as Cohen\&Levinthal (1990) [19], Lane \& Lubatkin (1998) [20] and Zahra\&George (2002) [21]. It was first put forward by Cohen and Levinthal (1990) [19], and was defined as the capacity of realizing the value of new information, absorbing and applying new information into commercial ends. Lack of absorptive capacity is one of the most important factors that hinder the effectiveness of knowledge transfer (Szulanski, 1996) [22].

Organizational distance can increase the difficulty of absorbing and transferring knowledge for enterprises,

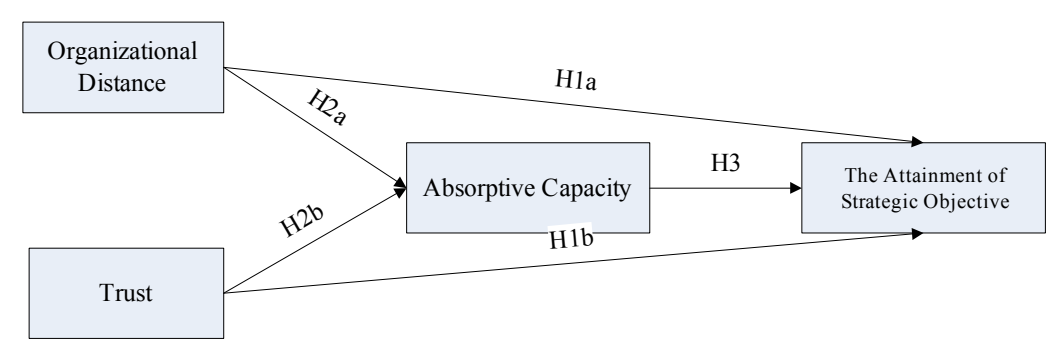

Figure 1. Theoretical model of strategic management knowledge transfer. 
since the two sides have to invest more time in the aspects of mutual communication, design of organizational routines and the development of mutual management system (Mowery, Oxley, Silverman, 1996) [23]. Hence,

Hypothesis 2a: The larger the organizational distance between MNC HQ and Chinese subsidiary, the weaker the absorptive capacity of Chinese subsidiary in the process of strategic management knowledge transfer.

Trust can influence the extent of knowledge exchange of IJVs (Inkpen, 1997) [16] and the exchange efficiency (Parkhe, 1993) [24]. Trust can also lower the knowledge transfer cost, and increase the possibility of absorbing and retaining new knowledge (Currall \& Judge, 1995) [25]. Hence,

Hypothesis 2b: The stronger of trust between $M N C$ $H Q$ and Chinese subsidiary, the stronger the absorptive capacity of Chinese subsidiary in the process of strategic management knowledge transfer.

\subsection{The Attainment of Strategic Objective of Chinese Subsidiary}

Some scholars used the perceived performance to measure the firm performance rather than financial indices. It was found that there was close relationship between the perceived performance indices and those financial ones (Geringer \& Herbet, 1991) [26]. The attainment of strategic objective was used as dependent variable in the study of Yan \& Gray (1994) [27], and will also be adopted n this paper.

Absorptive capacity can influence organizational performance (Cohen \& Levintha, 1990) [19]. Absorptive capacity is a function of past knowledge stock (Dierickx \& Cool, 1989) [28], and it plays a more and more important role in evaluating, transferring and applying new knowledge (Szulanski, 1996) [22].

Lyles \& Salk (1996) believed the more the IJVs learned from parent companies, the higher their performance would be. Tsai (2001) [29] also agreed on the positive relationship between subsidiaries' absorptive capacity and organizational performance. Hence,

Hypothesis 3: The stronger the absorptive capacity of Chinese subsidiary in the process of strategic management knowledge transfer, the more attainment of strategic objective of it.

\section{Methods}

\subsection{Sample}

The population of this study consists of Chinese subsidiaries in the form of both IJV and wholly-owned venture. The respondents would be TMT members in Chinese subsidiaries, including both foreign and Chinese TMT members, so two language version questionnaires were adopted based on two-way translation to guarantee the content validity. 7-point Likert-type scales were adopted, ranging from "strongly disagree" to "strongly agree". These scales were reverse-coded where appropriate.

115 effective questionnaires out of 257 ones were collected through two channels from February to August, 2009, with 35 by Email to MNC subsidiary directly, 80 by collecting in EMBA and TMT class. Group difference analysis was conducted showing no statistical significance.

Among the 115 questionnaires, 75 (65.2\%) is whollyowned venture, while IJV is $40(34.8 \%)$; the home countries of Chinese subsidiaries are mainly from US (21), European countries (43), South Korea (28), Japan (12); the industries mainly consist of manufacturing, telecommunication, electronics, food, finance etc.

\subsection{Instrument and Measures}

Measures of organizational distance were directly adopted from Simonin (1999b) [8] and adjusted to this research. Measures of trust were adjusted from Rempel \& Holmes (1986) [30], combining the specific characteristics of Chinese subsidiaries. In the pretest, it was found that the CITC (Corrected Item-Total Correlation, CITC) value of one item was less than 0.5 ; meanwhile the Cronbach Alpha of trust scale would increase after deleting it. Therefore, this item was removed in the final empirical test. Measures of absorptive capacity were directly adopted from Szulanski (1996) [22]. The attainment of strategic objective of Chinese subsidiary was measured by two items, implementing Yan\&Gray's (1994) [27] subjective method from both the subsidiary and HQ sides.

\section{Results and Analyses}

Amos 7.0 and SPSS 12.0 were the main statistical tools, and structural equation model (SEM) was used to analyze the theoretical model, which is suitable for both observed and unobserved variables (Bagozzi \& Philips, 1982) [31].

Alpha is used to evaluate the reliability level of scales. The constructs display satisfactory levels of reliability as indicated by composite reliabilities ranging from 0.721 to 0.853 . All the factor loadings were higher than 0.6 , above the critical threshold of 0.5 , showing high convergent validity of the scales. Meanwhile, no factor loading above 0.5 fell on two factors simultaneously, showing high discriminate validity.

According to the statistical results of the SEM (Referring to Figure 2), absorptive capacity had significant positive effect on the attainment of strategic objective. The hypotheses of the relationship between organizational distance, trust, absorptive capacity and the attainment of strategic objective were partially testified. 


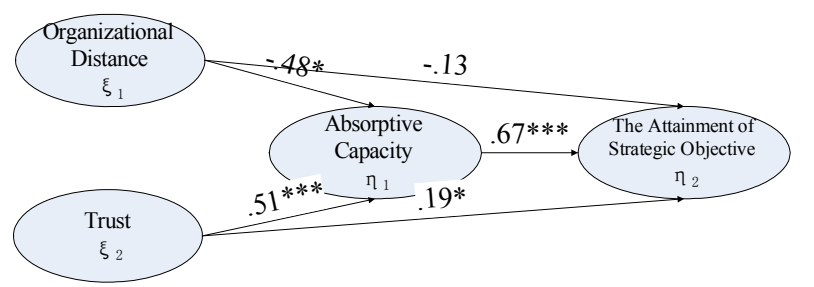

Figure 2. Result of Structural Equation Model Analysis.

According to the statistical results, the negative effect of organizational distance on the attainment of strategic objective $(\gamma 12=-0.13)$ was found nonsignificant. While the effect of trust was significant $(\gamma 22=0.19, \mathrm{p}<0.10)$, therefore hypothesis $1 \mathrm{~b}$ was testified.

The nonsignificance of the effect of organizational distance on the attainment of strategic objective could be attributed to the mediating effect of absorptive capacity, that is, absorptive capacity reduces the direct influence between the two variables. Therefore, in the practical operation of strategic management knowledge transfer, absorptive capacity should be paid enough attention by both MNC HQs and Chinese subsidiaries, since it will influence the knowledge transfer result and the attainment of Chinese subsidiaries' strategic objective.

Actually the effect of trust on the attainment of strategic objective was significant only on the confidence level of 0.10 . It showed that mutual communication and interaction between MNCs' HQ and subsidiaries play a critical role in the strategic management knowledge transfer, and meanwhile the stronger trust leads to more attainment of strategic objective.

According to the statistical results, both hypothesis 2a and $2 b$ were testified. Specifically, the negative effect of organizational distance $(\gamma 11=-0.48, \mathrm{p}<0.10)$, and the positive effect of trust $(\gamma 21=0.51, \mathrm{p}<0.001)$ on absorptive capacity were all found significant.

The positive effect of absorptive capacity on the attainment of strategic objective was found significant $(\beta 12$ $=0.67, \mathrm{p}<0.001$ ), so hypothesis 3 was verified.

Firm type was used as control variable to explore the influence of wholly-owned Chinese subsidiary outnumbering the IJVs in the current Chinese market. Analysis of Variance (ANOVA) was conducted to see whether or not there was significant difference for all the latent variables under the classification of firm type. It turned out that there was significant difference for absorptive capacity $(\mathrm{F}$ value $=13.75, \mathrm{p}<0.001)$ and the attainment of strategic objective $(\mathrm{F}$ value $=6.48, \mathrm{p}<0.05)$, but no significant difference for the others.

Concerning the difference in the attainment of strategic objective, it's mainly due to the cultural and decision conflicts in IJV, causing much distraction in the practical operations in attaining the strategic objective; while the wholly-owned subsidiaries can focus on their objective well, using the resources more effectively to attain higher level of strategic objective.

\section{Discussion and Conclusion}

The operational definition of strategic management knowledge was re-defined. The past literatures mainly focused on the transfer of technology or R\&D knowledge, marketing and manufacturing knowledge, almost ignoring strategic management knowledge. This paper expanded the field of strategic management knowledge related researches to some extent, by focusing on the strategic management knowledge transfer between MNCs' HQ and Chinese subsidiaries.

In this paper, the sample completely came from the Chinese subsidiary of MNCs. However, if data from the HQ can be acquired, it will be more meaningful for practice. For the future researches, the dyadic level should be considered.

Strategic management knowledge transfer is one of the unavoidable topics for knowledge management, playing crucial role in the attainment of strategy objective. The perspective of organizational characteristics will shed some light on the direction of operational behaviors between the MNC HQs and Chinese subsidiaries. Due to the unobservable nature of strategic management knowledge, it costs most of MNCs lots of resources to transfer knowledge from the HQ to Chinese subsidiaries. Therefore, it's very imperative to lower the knowledge transfer cost and improve the transfer effectiveness.

\section{REFERENCES}

[1] B. Kogut and U. Zander, "Knowledge of the Firm and the Evolutionary Theory of the Multinational Corporation," Journal of International Business Studies, Vol. 24, No. 4, 1993, pp. 625-645. doi:10.1057/palgrave.jibs.8490248

[2] J. Barney, "Strategic Factor Markets: Expectations, Luck and Business Strategy," Management Science, Vol. 32, No. 10, 1986, pp. 1231-1241. doi: $10.1287 /$ mnsc. 32.10 .1231

[3] D. J. Teece, G. Pisano and A. Sheun, "Dynamic Capabilities and Strategic Management," Strategic Management Journal, Vol. 18, No. 7, 1997, pp. 509-533. doi:10.1002/(SICI)1097-0266(199708)18:7<509::AID-S MJ882>3.0.CO;2-Z

[4] B. L. Simonin, "Transfer of Marketing Know-How in International Strategic Alliances: An Empirical Investigation of the Role and Antecedents of Knowledge Ambiguity," Journal of International Business Studies, Vol. 30, No. 3, 1999, pp. 463-490. doi:10.1057/palgrave.jibs.8490079

[5] J. T. Mahoney and A. M. McGahan, "The Field of Strategic Management within the Evolving Science of Strategic Organization," Strategic Organization, Vol. 5, No. 1, 2007, pp. 79-99. doi: $10.1177 / 1476127006074160$ 
[6] R. Sanchez, "Strategic Product Creation: Managing New Interactions of Technology Markets, and Organizations," European Management Journal, Vol. 14, No. 2, 1996, pp. 121-138. doi:10.1016/0263-2373(95)00056-9

[7] Y.-Y. Wong, T. E. Maher and S. T. K. Luk, "The Hesitant Transfer of Strategic Management Know-How to Foreign Wholly Owned Subsidiaries in China," Management Research News, Vol. 25, No. 11, 2002, pp. 42-56. doi:10.1108/01409170210783232

[8] B. L. Simonin, "Ambiguity and the Process of Knowledge Transfer in Strategic Alliances," Strategic Management Journal, Vol. 20, No. 7, 1999, pp. 595-623. doi:10.1002/(SICI)1097-0266(199907)20:7<595::AID-S $\underline{\mathrm{MJ} 47>3.0 . \mathrm{CO} ; 2-5}$

[9] C. C. Baughn, J. H. Stevens, J. G. Denekamp and R. N. Osborn, "Protecting Intellectual Capital in International Alliances," Journal of World Business, Vol. 32, No. 2, 1997, pp. 103-117. doi:10.1016/S1090-9516(97)90002-X

[10] E. Mosakowski, "Strategy Making under Causal Ambiguity: Conceptual Issues and Empirical Evidence," Organization Science, Vol. 8, No. 4, 1997, pp. 414-442.

[11] C. J. Choi and S. H. Lee, "A Knowledge-Based View of Cooperative Interorganizational Relationships," In: P. Beamish and J. Killing, Eds., Cooperative Strategies: European Perspectives, The New Lexington Press, San Francisco, 1997, pp. 33-58.

[12] J. K. Butler, "Toward Understanding and Measuring Conditions of Trust," Journal of Management, Vol. 17, No. 3, 1991, pp. 643-663. doi:10.1177/014920639101700307

[13] B. Nooteboom, et al., "Effects of Trust and Governance on Relational Risk," Academy of Management Journal, Vol. 40, No. 2, 1997, pp. 308-338. doi:10.2307/256885

[14] A. Zaheer, B. McEvily and V. Perrone, "Does Trust Matter? Exploring the Effects of Interorganizational and Interpersonal Trust on Performance," Organization Science, Vol. 9, No. 2, 1998, pp. 141-159. doi:10.1287/orsc.9.2.141

[15] B. Uzzi, "The Sources and Consequences of Embeddedness for Economic Performance of Organizations: The Network Effect," American Sociological Review, Vol. 61, No. 4, 1996, pp. 674-698. doi:10.2307/2096399

[16] A. C. Inkpen, "An Examination of Knowledge Management in International Joint Ventures," In: P. W. Beamish and J. P. Killing, Eds., Cooperative Strategies: North American Perspectives, New Lexington Press, San Francisco, 1997.

[17] B. Kogut, "Joint Ventures: Theoretical and Empirical Perspectives," Strategic Management Journal, Vol. 9, No. 4, 1998, pp. 319-332. doi:10.1002/smj.4250090403

[18] A. C. Inkpen and P. W. Beamish, "Knowledge, Bargaining Power, and the Instability of International Joint Ventures," Academy of Management Review, Vol. 22, No. 1,
1997, pp. 177-202.

[19] W. M. Cohen and D. A. Levinthal, "Absorptive Capacity: A New Perspective on Learning and Innovation Administrative," Science Quarterly, Vol. 35, No. 1, 1990, pp. 128152. doi:10.2307/2393553

[20] P. J. Lane and M. Lubatkin, "Relative Absorptive Capacity and Interorganizational Learning," Strategic Management Journal, Vol. 19, No. 5, 1998, pp. 461-477. doi:10.1002/(SICI)1097-0266(199805)19:5<461::AID-S MJ953>3.0.CO;2-L

[21] S. A. Zahra and G. George, "Absorptive Capacity: A Review, Reconceptualization, and Extention," Academy of Management Review, Vol. 27, No. 2, 2002, pp. 185-203.

[22] G. Szulanski, "Exploring Internal Stickiness: Impediments to the Transfer of Best Practice within the Firm," Strategic Management Journal, Vol. 17, No. 1, 1996, pp. 27-43.

[23] D. C. Mowery, J. E. Oxley and B. S. Silverman, "Strategic Alliances and Inter-Firm Knowledge Transfer," Strategic Management Journal, Vol. 17, 1996, pp. 77-91.

[24] A. Parkhe, "Strategic Alliance Structuring: A Game Theoretic and Transaction Cost Examination of Interfirm Cooperation," Academy of Management Journal, Vol. 36, No. 4, 1993, pp. 794-829. doi:10.2307/256759

[25] S. C. Currall and T. A. Judge, "Measuring Trust between Organizational Boundary Role Persons," Organizational Behavior and Human Decision Processes, Vol. 64, No. 2, 1995, pp. 151-170. doi:10.1006/obhd.1995.1097

[26] J. M. Geringer and L. Hebert, "Measuring Performance of International Joint Ventures," Journal of International Business Studies, Vol. 22, No. 2, 1991, pp. 249-264. doi:10.1057/palgrave.jibs.8490302

[27] A. Yan and B. Gray, "Bargaining Power, Management Control, and Performance in United States-China Joint Ventures: A Comparative Case Study," Academy of Management Journal, Vol. 37, No. 6, 1994, pp. 1478-1517. doi: $10.2307 / 256796$

[28] I. Dierickx and K. Cool, "Asset Stock Accumulation and Sustainability of Competitive Advantage," Management Science, Vol. 35, No. 12, 1989, pp. 1504-1511. doi:10.1287/mnsc.35.12.1504

[29] W. Tsai, "Knowledge Transfer in Intraorganizational Networks: Effects of Network Position and Absorptive Capacity on Business Unit Innovation and Performance," The Academy of Management Journal, Vol. 44, No. 5. 2001, pp. 996-1004. doi:10.2307/3069443

[30] J. K. Rempel and J. G. Holmes, "How Do I Trust Thee?" Psychology Today, February 1986, pp. 28-34.

[31] R. P. Bagozzi and L. W. Philips, "Representing and Testing Organizational Theories: A Holistic Construal," Administrative Science Quarterly, Vol. 27, No. 3, 1982, pp. 459-489. doi:10.2307/2392322 